\title{
ANALISIS USAHATANI ASPARAGUS ( Asparagus oficinialis L.) DI KELOMPOK TANI MERTANADI, DESA PELAGA, KECAMATAN PETANG, KABUPATEN BADUNG
}

\author{
Dewa Putu Swandana, S.P
}

Program Studi Agribisnis, Fakultas Pertanian, Universitas Dwijendra,

Email: dewaswandana@gmail.com

\begin{abstract}
Abstrak
Komoditi unggulan sektor pertanian seperti asparagus telah menjadi sumber pendapatan bagi masyarakat di Desa Pelaga, Kecamatan Petang, kabupaten Badung. Asparagus merupakan komoditi yang pontensial dalam memberikan kontribusi pada pendapatan keluarga petani. Penelitian ini bertujuan untuk mengetahui biaya, penerimaan, pendapatan, kelayaan usahatani (R/Cratio), dan kendala - kendala yang dihadapi petani dalam usahatani asparagus di Kelompok Tani Mertanadi, Desa Pelaga, Kecamatan Petang, Kabupaten Badung.

Hasil penelitian menunjukan bahwa dari 30 petani sampel di Kelompok Tani Mertanadi, biaya total yang dikeluarkan petani untuk usahatani asparagus adalah mencapai $\mathrm{Rp} 8.647 .100 /$ luas garapan/ tahun penerimaan rata - rata petani asparagus adalah Rp72.364.095/luas garapan/tahun, sehingga pendapatan petani asparagus adalah $\mathrm{Rp}$ 63.716.995/luas garapan/tahun hasil analisa menunjukan besarnya R/C ratio adalah 7,36. Kendala-kendala yang dihadapi oleh petani asparagus di Kelompok Tani Mertanadi adalah pada saat musim kamarau petani kekurangan air, ketika musim hujan petani arus menaungi bedengan agar tidak terlalu lembab dan, organisme penggangu tanaman (OPT) antara lain: bercak daun, ulat grayak, ulat tanah, jamur batang.
\end{abstract}

Kata Kunci : Pendapatan Petani, Usahatani asparagus

\begin{abstract}
Abtract
One of the leading commoditities of angricultur sector such as asparagus hasa become a source of income for the society in pelaga village, petang district, badung regency. Asparagus is a potential commodity in contributing to the income feasibility of farming ( $\mathrm{R} / \mathrm{C}$ ratio), and contraints faced by farmers in asparagus farming in the Mertanadi Farmer Grouf, Pelaga village, Petang District, Regency Badung.

The research results show of from 30 sample farmer in farmer groups, the total costs incurred by farming

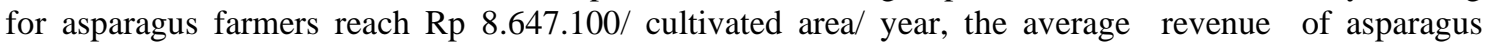
farmers is Rp 72.364.095/ cultivated area/ year, and for average income of asparagus farmer reach Rp 63.716.955/ cultivated area/ year. Analysis results show magnitude the $\mathrm{R} / \mathrm{C}$ is 7,36 . Contrais faced by asparagus farmer in the farmers in the farmer group Mertanadi are daring summer the Farmers are short the water, when the rainy season the farmers flow overshadow the beds so they are not most and organismeplant disturbing (OPT), among others: leaf spots, armyworms, soil caterpillars, stem fungi.
\end{abstract}

Keywords : Farmer income, Asparagus Farm

\section{PENDAHULUAN}

Indonesia merupakan Negara agraris yangmemiliki lahan subur dan luas serta cocok dijadikan lahan pertanian.Kegiatan pertanian dijadikan tumpuan bagi sebagian besar masyarakat Indonesia khususnya di daerah perdesaan. Pada era globalisasi meningkatnya sumber daya manusia dan berkembangnya teknologi minat generasi muda untuk menggeluti dunia pertanian kian membaik dalam menciptakan pikiran yang kreaktif dan inovatif dalam memproduksi tanaman untuk mendapatkan profit yang maksimal (Anonim 2011). Salah satu tanaman hortikultura yang sesuai dengan iklim tropis, yang banyak dijumpai dan sudah dibudidayakan oleh petani salah satunya adalah asparagus(Asparagus setaceus), tanaman asparagus merupakan salah satu tanaman sayur yang bersemak atau tanaman perdu yang hidup di tanah tinggi atau pegunungan.

Tanaman asparagus berasal dari mediterania di Eropa selatan. Tanaman ini dikenal oleh bangsa romawi ratusan tahun yang lalu sebelum masehi. Banyak varietas dari tanam asparagus namun 
hanyasekitar 20 jenis saja yang dapat dikomsumsi, asparagus merupakan sayuran memiliki khasiat dan kandungan vitamin tersendiri, terutama menghindari segala penyakit. Tanaman asparagus merupakan salah satu tanaman sayuran yang dikomsumsi banyak masyarakat di dunia walaupun di Indonesia sendiri bukanlah sayuran yang dihidangkan sehari-hari, juga banyak menyukai sayuran asparagus. Tanaman asparagus dikenal cukup mahal dan hanya disediakan oleh hotel berbintang.

Salah satu komoditi unggulan sektor pertanian seperti asparagus telah menjadi sumber pendapatan bagi masyarakat di Desa Pelaga, Kecamatan Petang, Kabupaten Badung. Asparagus merupakan komoditi yang pontensial dalam memberikan kontribusi pada pendapatan keluarga petani. Hasil panen petani langsung di pasarkan oleh lembaga koperasi itu sendiri dengan tingkat harga yang tinggi sehingga petani mendapatkan keuntungan yang signifikan. Desa Pelaga, Kecamatan Petang kawasan badung utara ini namanya mencuat bahkan keranah internasional hal ini karena produksi sayur asparagus yang menjadi perimadona dikawasan sejuk ini.

Kerjasama antara Pemerintah Kabupaten Badung serta pembinaan ahli pertanian dari yayasan Internasional Comperation and Development Fund (ICDF) dari Taiwan yang sudah berjalan 5 tahun, Desa Pelaga mampu menghasilkan asparagus dengan kualitas terbaik,bahkan disebut-sebut berkualitas terbaik di Asia,perkembangan sektor pertanian yang dikemas dalam program'One village, One product ini mampu meningkatkan taraf hidup keseruruhan di Desa Pelaga. Menariknya usahatani Asparagus dibudidayakan, banyak para perantau yang sudah memiliki perkerjaan yang bagus di kota balik lagi ke desa turut mengembangkan pertanian.

Usahatani Asparagus, dari sisi pendapatan memang sangat mengiurkan karena petani yang menaman asparagus dengan baik dan intens mampu mengasilkan Rp 600,000 hingga $\mathrm{Rp} 1,000,000$ perhari tentu tergantung dari luas lahannya, ini karena asparagus memiliki nilai ekonomis tinggi ketika di pasarkan di Badung selatan seperti hotel atau restoran pendapatan besar petani juga karena pebentukan koperasi yang menangani bibit pupuk hingga pemasaran sehingga petani terhindar dari tengkulak dan permainan harga (Anonim, 2011). Kualitas asparagus Pelaga sudah teruji di laboratorium sebagai sayuran berkualitas tinggi, bahkan terbaik di Asia, kualitasnya sudah diakui bahkan beberapa Negara di dunia meskipun belum bisa memasok banyak keluar negeri, karena untuk pasar lokal saja masih kewalahan. Dengan keunggulan asparagus tersebut peneliti ingin mengetahui berapa besar biaya, penerimaan, pendapatan dan R/C ratio usahatani asparagus pada Kelompok Tani Mertanadi, Desa Pelaga, Kecamatan Petang Kabupaten Badung.

\section{METODE}

Penelitian ini dilakukan pada Kelompok Tani Mertanadi, Desa Pelaga, Kecamatan Petang, Kabupaten Badung. Pemilihan lokasi ini ditentukan secara purposive sampling yaitu teknik penentuan sampel lokasi secara sengaja atau dengan pertimbangan tertentu. Adapun pertimbangannya adalah Pengembangan usahatani Asparagus sangat potensial baik secara ekonomi dan sosial dan Desa Pelaga memiliki dimensi agroklimat yang sangat mendukung untuk pengembangan asparagus. Populasi pada penelitian ini adalah seluruh anggota Kelompok Mertanadi yang berjumlah 30 orang. Teknik pengambilan sampel pada penelitian ini menggunakan metode sensus sehingga seluruh populasi dijadikan 
responden. Data yang digunakan dalam penelitian ini meliputi data primer dan data sekunder baik yang bersifat kualitatif sedangkan teknik pengumpulan data dilakukan dengan menggunakan kuesioner, wawancara, observasi, dan dokumentasi. Metode analisis data yang digunakan dalam penelitian ini adalah analisis usahatani yang terdiri dari biaya, penerimaan, pendapatan, dan $\mathrm{R} / \mathrm{C}$ ratio untuk menghitung kelayakan.

\section{HASIL DAN PEMBAHASAN}

\section{Gambaran Umum Daerah Penelitian}

Desa Pelaga merupakan salah satu desa yang termasuk wilayah Kecamatan Petang, Kabupaten Badung, Provinsi Bali. Lokasi ini dapat ditempuh dengan jalan darat, jarak dari Kota Denpasar $\pm 47 \mathrm{~km}$ atau 1 jam perjalan dan terletak $15 \mathrm{~km}$ dari kota kecamatan petang. Desa ini terletak diantara dua daerah tujuan wisata yaitu: obyek wisata bedugul dan obyek wisata kintamani yang banyak dikunjungi wisatawan domestik maupun wisatawan asing.

Desa Pelaga terletak pada ketinggian berkisar antara 650 - 1.110 meter dari permukaan laut. Desa Pelaga memiliki luas wilayah 3545,20 hektar, yang beriklim normal. Curah hujan rata-rata $2135 \mathrm{~mm}$ pertahun dengan temperature rata rata 24,4 derajat celcius. Kelembaban rata - rata 92,5\% dan tekanan rata - rata 1009,6 mm dengan penyinaran sinar matahari $60 \%$. Hujan jatuh pada bulan oktober sampai dengan bulan april dan hujan terbanyak jatuh pad bualan Desember hingga bulan januari Tofografi daerahnya berbukit - bukit dengan kemiringan $62^{\circ}$. Oleh karena itu, lahan pertanian umunya dibuat bertingkaat - tingkat dalam bentuk terasering.

Berdasarkan stastitik jumlah Penduduk Desa Pelaga sebanyak 6.096 orang, yang terdiri dari 3.072 orang ( $50,40 \%)$ laki- laki dan 3.024 orang $(49,60 \%)$ perempuan. Sebagian besar 2.334 orang (39.27 \%) Penduduk Desa Pelaga Yang tamat Sekolah Menengah Atas kemudian, 1,544 Orang ( 25,33\% ) yang tamat Sekolah Menengah Pertama, disusul tamatan perguruan Tinggi 489 orang( 08,02 \%). Dari segi mata pencarian yang, penduduk Desa Pelaga sebagian besar 4.717 Orang 77,40 \% bekerja di sektor Pertanian karena Desa Pelaga Memiliki Lahan Perkebunan yang luas dan sangat cocok dijadikan lahan pertanian, kemudian yang mengeluti perkerjaan Pedagang sebesar 167 Orang 2,73\% , Sejumlah masyarakat juga menjadi pegawe Negeri Sipil (PNS) 98 Orang 1,61\%, dan sebagian kecil Masyarakat menjadi ABRI 17 Orang ), $27 \%$.

\section{Biaya Uahatani Asparagus}

Berdasarkan pada hasil penelitian terhadap petani sampel, diperoleh bahwa rata - rata biaya total dikeluarkan petani untuk usahatani asparagus pada setiap luas garapan petani sampel adalah Sebesar Rp 8.647.100. Adapun rincian biaya asparagus yang digarab petani dapat diuraikan pada Tabel 1. Biaya sarana produksi terdiri dari biaya pupuk, festisida, tenaga kerja dan penyusutan alat yang digunakan pada usahatani asparagus dapat diuraikan sebagai berikut:

1. Pupuk

Pupuk yang digunakan oleh petani sampel asparagus di Kelompok Tani Merta Nadi Per tahunya adalah pupuk kandang, pupuk TSP, Pupuk KCL, Pupuk mutiara dan pupuk orea, jumlah masing - 
masing pupuk yang digunakan beserta harganya adalah, Pupuk Kandang 75 sak harga persaknya Rp 20.000, sehingga nilainya Rp 1.500.000. Pupuk TSP dan $\mathrm{KCl}$ masing - masing digunakan sebanyak $75 \mathrm{~kg}$ dengan harga perkilonya Rp 10.000 jadi nilanya Rp 750.000. Pupuk Mutiara dipergunakan sebanyak $40 \mathrm{Kg}$ harga per kilonya 13.000 Sehingga nilainya Rp 520.000.pupuk orea yang digunakan sebanyak $75 \mathrm{Kg}$, harga per kilonya Rp 8.000 sehingga harga totalnya 600.000

2. Pestisida

Pestisidayang digunakan petani sampel asparagus di Kelompok Tani Merta Nadi pertahunya adalah Antrakol dan Maxicen. Antrakol dipergunakan sebanyak 12Kg dan harga perkilonya Rp 65.000 jadi nilanya Rp780.000. Pestisida Maxicen jumlah digunakan sebanyak 8,5 liter sedangakan harga perliternya Rp 95.000 jadi jumlah totalnya adalah Rp 807.500.

3. Penyusutan Alat dan Tenaga Kerja

Alat - alat yang digunakan petani asparagus adalah sabit, sprayer, geregaji. Kapak, cangkul, plastik trasparan, tali plastik, ajir ( tiang bambu ) dan traktor masing - masing alat digunakan berturut - turut 5 tahun.Tenaga kerja yang digunakan petani asparagus di Kelompok Tani Merta Nadi, yang dibayar per hari Rp100,000 dan selama 1 bulan buruh bekerja selama 15 Hok. Secara rinci biaya - biaya yang dikeluarkan petani disajikan pada Tabel 1.

Tabel 1. Rincian rata-rata Biaya Usahatani Asparagus/luas garapan/tahun di Kelompok Tani Mertanadi Desa Pelaga, Kecamatan Petang, Kabupaten, Badung

\begin{tabular}{|c|c|c|c|c|c|c|}
\hline No & Komponen & Jumlah & Satuan & $\begin{array}{c}\text { Harga } \\
\text { Satuan } \\
(\mathbf{R p}) \\
\end{array}$ & $\begin{array}{c}\text { Nilai } \\
\text { Penyusutan } \\
(\mathrm{Rp})\end{array}$ & Jumlah (Rp) \\
\hline \multirow[t]{11}{*}{1} & 1. Biaya Tetap & & & & & \\
\hline & a. Sabit & 2 & $\mathrm{Bh}$ & $50.000,-$ & 10.000,- & $10.000,-$ \\
\hline & b. Sprayer & 1 & $\mathrm{Bh}$ & 499.000,- & 99.800,- & 99.800,- \\
\hline & c. Gergaji & 3 & $\mathrm{Bh}$ & $25.000,-$ & 15.000,- & $15.000,-$ \\
\hline & d. Kapak & 2 & $\mathrm{Bh}$ & $60.000,-$ & $24.000,-$ & $24.000,-$ \\
\hline & e. Cangkul & 4 & $\mathrm{Bh}$ & $85.000,-$ & $68.000,-$ & $68.000,-$ \\
\hline & f. Plastik & 4 & Rol & $275.000,-$ & $220.000,-$ & $220.000,-$ \\
\hline & g. Tali & 3 & Ikat & 305.000,- & 183.000,- & 183.000,- \\
\hline & h. Ajir & 40 & $\mathrm{Bh}$ & $40.000,-$ & $320.000,-$ & $320.000,-$ \\
\hline & i. Sewa Traktor & 1 & Hari & 499.800,- & & 499.800,- \\
\hline & j. Tenaga Kerja & 15 & Hok & 100.000,- & & 1.500.000,- \\
\hline \multirow[t]{8}{*}{2} & 2. Biaya Variabel & & & & & \\
\hline & $\begin{array}{ll}\text { a. } & \text { Pupuk } \\
& \text { Kandang }\end{array}$ & 75 & Sak & $20.000,-$ & & 1.500.000,- \\
\hline & b. TSP & 75 & $\mathrm{Kg}$ & 10.000,- & & $750.000,-$ \\
\hline & c. $\mathrm{KCL}$ & 40 & $\mathrm{Kg}$ & $10.000,-$ & & $750.000,-$ \\
\hline & d. Mutiara & 75 & $\mathrm{Kg}$ & 13.000,- & & $250.000,-$ \\
\hline & e. Urea & 75 & $\mathrm{Kg}$ & $8.000,-$ & & $600.000,-$ \\
\hline & f. Antracol & 12 & $\mathrm{Kg}$ & $65.000,-$ & & $780.000,-$ \\
\hline & g. Maxicen & 8,5 & Ltr & $95.000,-$ & & $807.500,-$ \\
\hline \multicolumn{6}{|c|}{ Total } & 8.647.100,- \\
\hline
\end{tabular}

Sumber : Olahan Data Primer 


\section{Penerimaan, Pendapatan dan R/C Ratio Usahatani Asparagus}

Penerimaan petani asparagus di Kelompok Tani Mertanadi Khususnya yang memproduksi asparagus diperoleh dengan cara mengalikan jumlah produksi asparagus rata - rata perluas garapan, dengan harga rata - rata produksi asparagus (di tingkat petani) yang berlaku saat penelitian. Berdasarkan hasil penelitian, rata- rata asparagus yang dihasilkan oleh petani adalah $2.097,51 \mathrm{~kg} / \mathrm{luas}$ garapan/tahun, atau rata- rata asparagus yang dihasilkan oleh petani adalah $10.201,89 \mathrm{~kg} / \mathrm{hektar} / \mathrm{tahun}$,rata-rata harga asparagus di tingkat petani adalah $\mathrm{Rp} 34,500 / \mathrm{kg}$ dengan kisaran antara $\mathrm{Rp} 20.330,66 / \mathrm{kg}$ sampai $\mathrm{Rp}$ $52.310,66 / \mathrm{kg}$, oleh karena dapat diperhitungkan besar rata-rata penerimaan petani asparagus yaitu Rp72.364.095/luas garapan/tahun, atau Rp 351.965.500/hektar/tahun.

Hasil analisis usahatani terhadap tanaman asparagus, pendapatan petani diperoleh dengan cara menghitung selisih antara rata- rata penerimaan dengan total biaya . Berdasarakan perhitungan, diperoleh

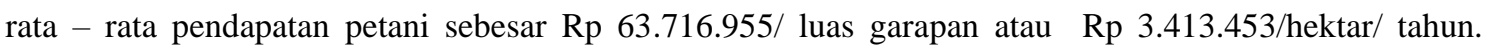
Secara lebih rinci, perhitungan penerimaan usatani asparagus dapat dilihat pada Tabel 2.

Tabel 2. Rata-rata Penerimaan, Pendapatan dan R/C Ratio Usahatani Asparagus Selama 1 Tahun di Kelompok Tani Mertanadi, Desa Pelaga, Kecamatan Petang, Kabupaten Badung

\begin{tabular}{|c|c|c|c|}
\hline Total Biaya & Penerimaan & Pendapatan & R/C Ratio \\
\hline Rp 8.647.100,- & Rp 72.364.095,- & Rp 63.716.955,- & 7,36 \\
\hline
\end{tabular}

Sumber : Olahan Data Primer

Berdasarkan pada hasil perhitungan terlihat bahwa rata - rata penerimaan petani dari usahatani asparagus adalah sebesar Rp 72.364.095/ luas garapan/tahun, rata - rata perluas garapan adalah 20,33are , atau penerimaan dikeluarkan petani asparagus adalah sebesar Rp 351.965.500/Ha/ tahun.

Memperhatikan besarnya nilai rata - rata penerimaan dan biaya total yang digunakan untuk kegiatan usahatani asparagus dapat dihitung efisiensinya. Efsinsiensi ini diukur dengan menghitung rasio antara penerimaan dengan biaya. Hasil perhitungan menunjukan bahwa $\mathrm{R} / \mathrm{C}$ rationya adalah sebesar 7,36. Ini berarti setiap tambahan 1 unit biaya yang digunakan untuk usahatani asparagus akan memberikan tambahan penerimaan sebesar 7,36 unit. Dengan demikian usahatani asparagus yang diusahakan oleh petani di Kelompok Tani Merta Nadi, Desa Pelaga, Kecamatan Petang Kabupaten Badung Memiliki tingkat efisiensi yang baik, dan sangat layak diusahakan, karena memiliki RC ratio lebih besar daripada 1( satu).

\section{Kendala - Kendala Dalam usahatani Budidaya Asparagus}

Produksi petani asparagus di Desa Pelaga, kecamatan Petang, Kabupaten Badung terdapat pula berbagai kendala - kendala dalam membudidayakan asparagus, seperti pada saat musim hujan, musim kamarau dan pengendalian hama dan penyakit yang menyerang tanaman asparagus, karena serangan hama dan penyakit ini dapat mempengaruhi produksi asparagus. Beberapa kendala - kendala yang dihadapi petani dalam pengembangan tanaman asparagus secara rinci dapat dilihat pada Tabel 3 . 
dwijenAGRO Vol. 10 No. 1, Mei 2020 ISSN : 1979-3901

Tabel 3. Kendala- kendala dihadapi Usahatani asparagus di kelompok Tani Merta Nadi Tahun 2019.

\begin{tabular}{|c|l|c|c|}
\hline No & \multicolumn{1}{|c|}{ Jenis Kendala } & Frekuensi & Presentase \\
\hline 1 & Musim hujan & 6 & 20,03 \\
\hline 2 & Musim kamarau & 7 & 10,00 \\
\hline 3 & Bercak daun & 4 & 13,03 \\
\hline 4 & Ulat grayak & 5 & 16,06 \\
\hline 5 & Ulat tanah & 5 & 16,06 \\
\hline 6 & Jamur Batang & & 30 \\
\hline & Jumlah & & \\
\hline
\end{tabular}

Sumber : Olahan Data Primer

Berdasarkan tabel diatas menunjukan bahwa 6 orang petani 20,00\% mengatakan kendala - kendala yang dihadapi adalah, pada saat musim kamarau petani kekurangan air untuk penyiraman dan pemupukan, disusul 7 orang petani $23,03 \%$ menyebutkan kendala yang dihadapi petani adalah pada saat musim hujan petani arus menaungi bedengansupaya bedengan tidak lembab dan tanaman asparagus tidak terlalu banyak terkena air hujan yang menyebabkan tanaman lebih mudah terserang penyakit, disusulsebanyak 3 orang petani 10\% mengatakan kendala- kendala yang dihadapi adalah penyakit bercak daun yang menyerang tanaman asparagus yang menyebabkan petani mengalami kerugian, disusul sebanyak orang 29,09\% mengatakan kendala- kendala yang dihadapi adalah serangan hama ulat grayak dan ulat tanah yang menyerang tananaman asparagus yang menyebabkan tanaman asparagus rusak, dan menyebakan petani mengalami kerugian, dan 5 orang 16,06\% mengatakan kendala- kendala yang dihadapi adalah penyakit jamur batang yang menyerang tanaman, yang menyebabkan tanaman asparagus mati, sehingga petani mengalami kerugian total.

\section{PENUTUP}

\section{Simpulan}

Berdasarkan hasil dan pembahasan di atas dapat disimpulkan bahwa total biaya usahatani asparagus sebesar $\mathrm{Rp}$ 8.647.100,-, penerimaan sebesar $\mathrm{Rp}$ 72.364.095,-, pendapatan sebesar Rp 63.716.955,- dan R/C Ratio sebesar 7,36. Adapun kendala kendala yang dihadapi petani petani adalah kendala pada saat musim kamarau petani kekurangan air untuk memenuhi kebutuhan tanaman untuk penyiraman sedangakan pada saat musim hujan petani harus menaungi bedengan agar tidak lembab yang menyebabkan tananaman asparagus lebih mudah terserang.

\section{Saran}

Berdasarkan hasil analisis dan pembahasan yang telah dilakukan dalam penelitian ini, maka dapat diberikan beberapa saran sebagai yaitu (1) Petani sebaiknya bisa bekerja sama dalam mencari solusi untuk menghadapi berbagai kendala- kendala yang dihadapi petani asparagus antar petani satu ke petani yang lainya untuk menjaga tingkat produksi agar berkulitas baik, tentu untuk menjaga pendapatan petani (2) Pemerintah atau instansi yang berwenang hendaknya lebih memperhatikan usahatani asparagus, 
karena komoditas ini termasuk dalam komoditas ekspor, misalnya lebih sering memberikan penyuluhan penyuluhan yang dapat meningkatkan pengetahuan, keterampilan petani dengan harapan produktivitasnya meningkat pula.

\section{DAFTAR PUSTAKA}

Anonim.2003.Analisis Usahatani Hortikultura. Jakarta: direktorat pengembangan Usaha Hortikultura Depertemen pertanian RI

Bambang ,dkk. 2011. Dasar- dasar pembelanjaan perusaan. Yogyakarta: BPFE

Soekartawi. 1995. Analisis Usahatani. UI Press. Jakarta.

Hertanto, F .1989. Ilmu usahatani .Jakarta : penerbit swadaya

Hadisapoetra,S. 1997. Biaya pendapatan usahatani.Yogyakarta : departemen Ekonomi Gajah Mada.

Istijanto. 2010. Riset Sumber Daya Manusia .Jakarta : PT gramedia pustaka Utama.

Juknis 2009. Petunjuk teknik pengendalian OPT pada tanaman pestisida ramah lingkungan (APBD TA.2009). Bidang produksi Dinas Tanaman pangan Provinsi Bali.Denpasar

Kertasapoerta .1988 .Prinsip- prinsip Biaya Usahatani. Jakarta: Pt Gramedia

Mosher, A.T. 1987. Pergerakan dan pembagunan pertanian .Syarat-syarat pembagunan dan Modernisasi. Jakarta: CV .Yasaguna

Mubyarto.1995. Pengantar Ekonomi Pertanian .Jakarta :LP3ES 